\title{
Thermoregulation and the influence of body temperature on calling song parameters in Cicada orni (Hemiptera: Cicadidae)
}

\author{
Allen F. SANBORN ${ }^{1}$, Paula C. SIMÕES ${ }^{2}$, Polly K. PHILliPS ${ }^{3}$ and José A. QUARTAU ${ }^{2}$ \\ ${ }^{1}$ Department of Biology, Barry University, 11300 NE Second Avenue, Miami Shores, Florida 33161-6695, USA; \\ e-mail: asanborn@mail.barry.edu \\ ${ }^{2}$ Centro de Biologia Ambiental, Departamento de Biologia Animal, Faculdade de Ciências da Universidade de Lisboa, \\ 1749-016 Lisboa, Portugal; e-mails: pcsimoes@fc.ul.pt; jaquartau@fc.ul.pt \\ ${ }^{3} 17446$ SW 33 ${ }^{\text {rd }}$ Court, Miramar, Florida 33029, USA; e-mail: pkmcp31@illinoisalumni.org
}

Key words. Bioacoustics, calling song, Cicada, Cicadidae, temperature, thermoregulation

\begin{abstract}
Measurements of body temperature in the field demonstrate that Cicada orni Linnaeus regulates body temperature through behavioral mechanisms. Behavior is used to regulate body temperature to a range necessary for calling. As predicted, results showed a general decrease of echeme duration and an increase in inter-echeme interval with rising body temperature. However, no statistically significant correlations of body temperature for any of the variables studied were found, giving evidence that there is more variability in call parameters between individuals than any effect of body temperature.
\end{abstract}

\section{INTRODUCTION}

Cicada orni Linnaeus, 1758 (Hemiptera: Cicadidae) is one of the most abundant and common cicadas throughout the Mediterranean area. Like other cicadas, males of $C$. orni produce loud airborne acoustic sounds by means of an elaborated timbal mechanism (Claridge, 1985; Bennet-Clark, 1998). The calling song is the most common type of acoustic signal and it is involved in mate attraction, having an important role in pair formation and in species recognition (Claridge, 1985; Villet, 1992).

Acoustic activity is dependent on intrinsic and environmental factors. The daily fluctuation in ambient air temperature $\left(T_{a}\right)$ is one of the factors that may contribute to the regulation of song production in cicadas (Sanborn, 1997, 2002).

The study of temperature influences on acoustic insects has a long history (see review in Sanborn, 2005). Temperature influences biological reactions at the chemical level so the ability of an animal to coordinate acoustic activity is dependent on temperature. Cicadas are relatively large in comparison to most acoustic insects and can thermoregulate in an effort to minimize any influence of temperature on their mating signal (Sanborn, 2002). However, there are multiple studies that show temperature may or may not influence the acoustic signals of cicadas, depending on species.

The investigation of $T_{a}$ affect on the temporal parameters of cicada songs has led to contradictory results. Popov et al. (1997), Quartau et al. (2000), and Fonseca \& Revez (2002) have shown $\mathrm{T}_{\mathrm{a}}$ influences at least some temporal parameters of cicada songs while Popov (1975), Gogala et al. (1996), and Villet et al. (2003) show no relationship of cicada call parameters to $\mathrm{T}_{\mathrm{a}}$. Similar contradictory results have been shown with call intensity of cicada calls (Sanborn, 1997; Sueur \& Sanborn, 2003)
Cicadas generally thermoregulate (Sanborn, 2002) so their body temperature $\left(T_{b}\right)$ can be significantly different from $\mathrm{T}_{\mathrm{a}}$. Therefore, $\mathrm{T}_{\mathrm{b}}$ must be measured to determine if temperature is influencing call activity or parameters. We measured $\mathrm{T}_{\mathrm{b}}$ to determine if $C$. orni is thermoregulating and to determine if $\mathrm{T}_{\mathrm{b}}$ influences the call parameters of $C$. orni.

\section{MATERIAL AND METHODS}

A population of $C$. orni was sampled during 1 and 3 July 2010 in an olive (Olea europaea L.) grove $300 \mathrm{~m} \mathrm{E}$ of Beaumes-de-Venise $\left(44^{\circ} 7.273^{\prime} \mathrm{N}, 5^{\circ} 2.516^{\prime} \mathrm{E}\right)$, Vaucluse, Provence, France, with a single additional specimen captured in a vineyard (Vitis vinifera L.) in Vaison-la-Romaine $\left(44^{\circ} 15.315^{\prime} \mathrm{N}\right.$, $5^{\circ} 4.380^{\prime} \mathrm{E}$ ) on 2 July 2010 . $\mathrm{T}_{\mathrm{b}}$ was measured with a Physitemp BAT-12 digital thermocouple thermometer and a type MT-29/1 copper-constantan 29 gauge hypodermic microprobe accurate to $\pm 0.1^{\circ} \mathrm{C}$ which had been calibrated with a National Institute of Standards and Technology mercury thermometer. The probe was inserted midway into the dorsal mesothorax to record deep $\mathrm{T}_{\mathrm{b}}$. An insect net was constricted around a captured animal to reduce movement prior to inserting the probe. This procedure minimizes any heat transfer between the experimentor and the specimen. All measurements were recorded within $5 \mathrm{~s}$ of the animal being captured. Perch temperature $\left(T_{p}\right)$ was measured immediately after recording $T_{b}$ by placing the thermocouple tip above the perch where the animal was captured at the approximate height of the middle of the thorax $(5 \mathrm{~mm}) . \mathrm{T}_{\mathrm{a}}$ was measured at a height of about $1 \mathrm{~m}$ in the shade after $\mathrm{T}_{\mathrm{p}}$ was recorded. Records of the orientation to the sun and the position of the animal were made as the animal was captured.

The calling song of 11 males was recorded using a Sony Dat recorder (TCD-D10 ProII at a sampling frequency of $44.1 \mathrm{kHz}$, frequency response range of $20 \sim 22,000 \mathrm{~Hz}$, as in previous studies) which was connected to a dynamic Sony F-780 microphone (with frequency responses of 50 18,000 HZ). The microphone was placed medially and dorsally to the insect at a constant distance of approximately $30 \mathrm{~cm}$. After placing the microphone, 
TABLE 1. Description and summary of the acoustic variables analyzed for Cicada orni calls.

\begin{tabular}{|c|c|c|c|c|c|}
\hline Variable & Description & Mean & SD & $\min$ & $\max$ \\
\hline Echeme duration & Duration of each element from start to end (s) & 0.05 & 0.01 & 0.04 & 0.07 \\
\hline Inter-echeme interval & Duration between the end of one element and the beginning of the following one (s) & 0.23 & 0.06 & 0.17 & 0.35 \\
\hline No. of echemes/s & Number of elements per second $\left(\mathrm{s}^{-1}\right)$ & 4.71 & 1.04 & 3.03 & 6.15 \\
\hline Ratio echeme/interval & Ratio between the echeme duration and the inter-echeme interval (s) & 0.25 & 0.07 & 0.15 & 0.37 \\
\hline Peak frequency & Frequency of the maximum amplitude on the spectrum $(\mathrm{kHz})$ & 4.84 & 0.24 & 4.41 & 5.31 \\
\hline
\end{tabular}

recording commenced only when the normal calling pattern was re-established by the insect. Sound recordings were analyzed in the lab at the time and frequency domains using the software Avisoft-SASLab Pro (Specht, 2002).

In the frequency domain, spectra were computed using Fast Fourier transformation with a resolution of 512 points and a Hamming Window. For each specimen, whenever possible, one subsample of $30 \mathrm{~s}$ was chosen at random from each recording and several parameters were measured (Table 1). In the temporal domain, the duration of the echemes, the duration of the interval between them (inter-echeme interval), number of echemes per second and ratio echeme/interval were measured. Peak frequency was also obtained from the mean spectrum of each echeme. Variables were averaged and the mean was taken as the value of the parameter for each specimen. Due to chorusing cicadas in some samples, variables like the number of pulses per unit of time were discarded.

Statistical analyses were performed using InStat 3.0a for the Macintosh (GraphPad Software, San Diego, CA) and STATISTICA 9.0 software (StatSoft, 2009). Statistical significance is considered to be 0.05 for all tests. Statistics are reported as mean \pm standard deviation.

\section{RESULTS}

Regression analysis of $T_{b}$ as a function of $T_{a}$ (Fig. 1) produces slopes that are significantly different from one $(\mathrm{t}$ $=-6.811$, d.f. $=63, \mathrm{p}<0.0001)$ and zero $(\mathrm{t}=7.304$, d.f. $=$ $63, \mathrm{p}<0.0001)$. Similarly, regression analysis of $\mathrm{T}_{\mathrm{b}}$ as a function of $\mathrm{T}_{\mathrm{p}}$ (Fig. 2) produces slopes that are also significantly different from one $(\mathrm{t}=-7.151$, d.f. $=63, \mathrm{p}<$ $0.0001)$ and zero $\left(\mathrm{T}_{\mathrm{b}}\right.$ vs. $\mathrm{T}_{\mathrm{p}} \mathrm{t}=7.923$, d.f. $=63, \mathrm{p}<$ $0.0001)$. A slope of a regression significantly different from one or not significantly different from zero suggests

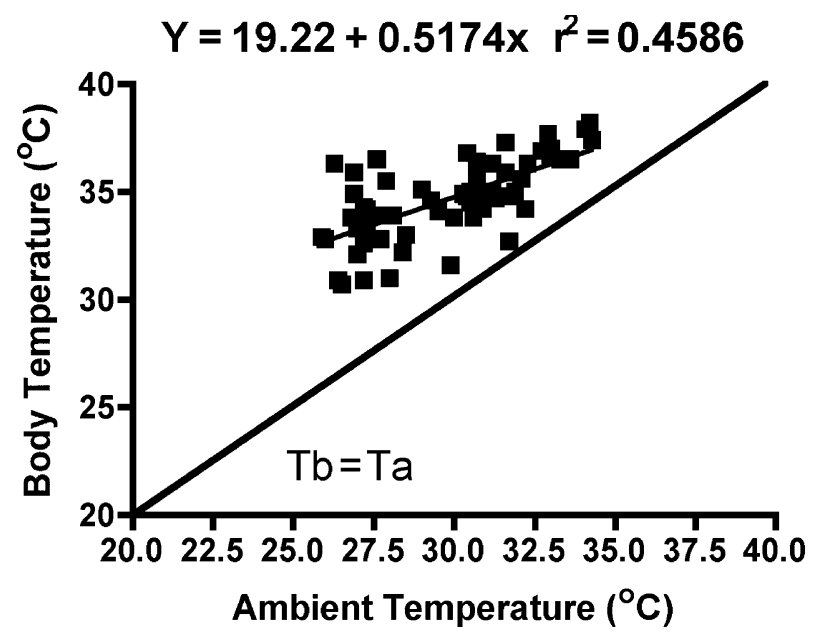

Fig. 1. Body temperature as a function of ambient temperature in Cicada orni. The slope is significantly different from one suggesting thermoregulation. thermoregulation is occurring (May, 1985). Thus the regressions suggest that $C$. orni is thermoregulating but the correlation coefficients and scatter of the data around the regression lines suggest $C$. orni is not very precise in the regulation of its $T_{b}$. The positive slopes show that $T_{b}$ increases more slowly than increases in $\mathrm{T}_{\mathrm{a}}$.

The mean $\mathrm{T}_{\mathrm{b}}$ of active $C$. orni was $34.67 \pm 1.79^{\circ} \mathrm{C}(\mathrm{n}=$ 65 , range $\left.30.7-38.2^{\circ} \mathrm{C}\right)$, mean $\mathrm{T}_{\mathrm{a}}$ was $29.87 \pm 2.34^{\circ} \mathrm{C}(\mathrm{n}=$ 65 , range $25.9-34.3^{\circ} \mathrm{C}$ ), and mean $\mathrm{T}_{\mathrm{p}}$ was $30.71 \pm 2.37^{\circ} \mathrm{C}$ $\left(\mathrm{n}=65\right.$, range $\left.26.5-35.7^{\circ} \mathrm{C}\right)$ during experimentation. There are also significant differences between mean $\mathrm{T}_{\mathrm{b}}$, $\mathrm{T}_{\mathrm{a}}$ and $\mathrm{T}_{\mathrm{p}}$ (ANOVA $\mathrm{F}=89.807$, d.f. $=2$, 192, $\mathrm{p}<$ 0.0001). A Tukey-Kramer Multiple Comparison Test shows that $\mathrm{T}_{\mathrm{b}}$ differs significantly from $\mathrm{T}_{\mathrm{a}}(\mathrm{q}=17.746, \mathrm{p}$ $<0.001)$ and $\mathrm{T}_{\mathrm{p}}(\mathrm{q}=14.637, \mathrm{p}<0.001)$ while $\mathrm{T}_{\mathrm{a}}$ does not differ from $\mathrm{T}_{\mathrm{p}}(\mathrm{q}=3.109, \mathrm{p}>0.05)$.

Cicada orni uses behavioral mechanisms to regulate $\mathrm{T}_{\mathrm{b}}$. Early in the activity period and at low $\mathrm{T}_{\mathrm{a}}, C$. orni are found in sunlit perches. As $\mathrm{T}_{\mathrm{a}}$ increases, the cicadas move to more shaded locations. At highest $\mathrm{T}_{\mathrm{a}}$ or $\mathrm{T}_{\mathrm{b}}, C$. orni is found in the deep shade on the underside of the main branches and on the trunks of trees. Calling behavior becomes inhibited as $\mathrm{T}_{\mathrm{a}}$ falls and C. orni appears to be strictly ectothermic.

The temporal characteristics of the calling songs of the studied individuals are presented in Table 1. The echeme has a mean duration of $0.05 \pm 0.01 \mathrm{~s}$ (range $0.04-0.07 \mathrm{~s}$ ) separated by intervals of $0.23 \pm 0.06 \mathrm{~s}$ (range $0.17-0.35$ $\mathrm{s}$ ). Echemes are repeated at a rate of $4.71 \pm 1.04 \mathrm{~s}^{-1}$ (range 3.03-6.15 s $\mathrm{s}^{-1}$ ) and with a ratio echeme/inter-echeme of $0.25 \pm 0.07 \mathrm{~s}$ (range $0.15-0.37 \mathrm{~s})$. The spectral character-

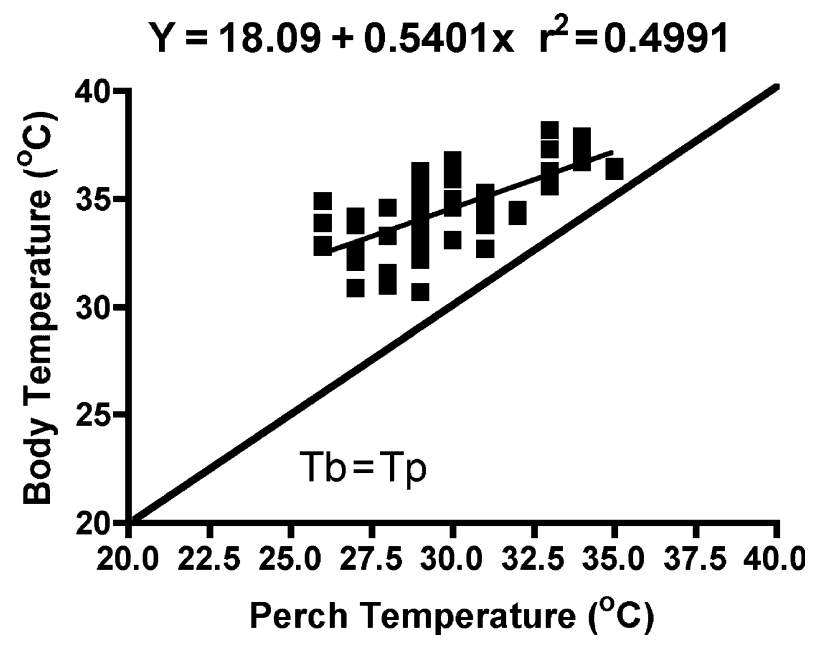

Fig. 2. Body temperature as a function of perch temperature in Cicada orni. The slope is once again significantly different from one suggesting thermoregulation. 
TABLE 2. Spearman Rank Order correlations coefficients between temperatures and acoustic variables of Cicada orni calling song. No correlations are significant at $\mathrm{p}<0.05$. $\mathrm{T}_{\mathrm{b}}-$ body temperature; $\mathrm{T}_{\mathrm{a}}-$ ambient temperature; $\mathrm{T}_{\mathrm{p}}-$ perch temperature.

\begin{tabular}{lrrr}
\hline Variable & $\mathrm{T}_{\mathrm{b}}$ & $\mathrm{T}_{\mathrm{a}}$ & \multicolumn{1}{c}{$\mathrm{T}_{\mathrm{p}}$} \\
\hline Echeme duration & -0.164 & 0.023 & -0.404 \\
Inter-ech. interval & 0.364 & 0.364 & -0.220 \\
Echemes/sec. & -0.382 & -0.323 & 0.119 \\
Ratio ech./int. & -0.600 & -0.478 & -0.165 \\
Peak frequency & 0.100 & -0.533 & -0.229 \\
\hline
\end{tabular}

istics of the signal showed a peak frequency of $4.84 \pm$ $0.24 \mathrm{kHz}$ (range $4.41-5.31 \mathrm{kHz}$ ).

As predicted, results showed a general decrease of echeme duration and an inter-echeme interval increase with rising $T_{b}$. However, the Spearman's correlation coefficients used to test the correlation between temperatures and acoustic parameters showed no statistically significant correlations at $p<0.05$ for any of the variables studied (Table 2).

\section{DISCUSSION AND CONCLUSIONS}

The statistical difference between mean $T_{b}$ and mean $T_{a}$ and mean $\mathrm{T}_{\mathrm{p}}$ and the regression analysis suggest that $C$. orni actively thermoregulates. Similar relationships between $T_{b}$ and $T_{a}$ have been found in both ectothermic and endothermic cicadas from North America, South America and Africa (Sanborn, 2000, 2004; Sanborn \& Maté, 2000; Sanborn et al., 1992, 1995b, 2002b, 2003, 2004; Villet et al., 2003). However, unlike the relationship seen in Diceroprocta olympusa (Walker, 1850) (Sanborn \& Maté, 2000), the thermoregulatory behavior of $C$. orni more closely resembles what was observed in the desert cicada Okanagodes gracilis Davis, 1919 (Sanborn et al., 1992) in that $T_{p}$ is not a better predictor of $T_{b}$ than $\mathrm{T}_{\mathrm{a}}$.

Sufficient solar radiation to elevate $T_{b}$ to a range necessary for activity is required to maintain activity in ectothermic cicadas (Heath, 1967; Sanborn \& Phillips, 1992; Sanborn \& Maté, 2000; Sanborn et al., 2002a, b). Cicada orni exhibits a classic pattern of behavioral thermoregulation by changing body orientation and perch position to alter the amount of radiant heat uptake from the sun in an effort to regulate $T_{b}$. The importance of solar radiation in $\mathrm{T}_{\mathrm{b}}$ regulation is illustrated by the minimum $\mathrm{T}_{\mathrm{a}}$ required for activity (Cloudsley-Thompson \& Sankey, 1957; Cloudsley-Thompson, 1960; Quartau et al., 2000) and the inhibition of calling activity with strong winds (which would increase convective heat loss and decrease the differences between $T_{b}$ and $T_{a}$ ) (Quartau et al., 2000). Inhibition of calling activity by low $T_{a}$ has been reported for multiple cicada species (see references in Sanborn, 1998).

Calling activity requires the coordination of nervous and muscle activity and can be coordinated over a defined range of $\mathrm{T}_{\mathrm{a}}$. The range of $\mathrm{T}_{\mathrm{b}}\left(7.5^{\circ} \mathrm{C}\right)$ for calling activity in C. orni is within the range reported for both ectothermic and endothermic species (Table 3 ). The mean $\mathrm{T}_{\mathrm{b}}$ of calling $C$. orni is significantly less than (one-tailed $\mathrm{t}=$ 2.655 , d.f. $=79, \mathrm{p}=0.0048$ but due to unequal standard deviations, Mann-Whitney U-statistic $=362.00, \mathrm{U}^{\prime}=$ $678.00, \mathrm{p}=0.0308$ ) the upper thermoregulatory point determined for the species (Sanborn et al., 2011) further suggesting the animals are regulating their $T_{b}$ below $a$ level where thermoregulation would take precedence over calling activity.

The positive slope of the regression line may explain the relationship of temporal parameters of $C$. orni to $\mathrm{T}_{\mathrm{a}}$

TABLE 3. Body temperature range for calling measured in cicada species. Endothermic species are marked with an asterisk $\left(^{*}\right)$. Platypedia putnami lutea is a crepitating cicada rather than a timballing species.

\begin{tabular}{|c|c|c|}
\hline Species & Body temperature range for calling $\left({ }^{\circ} \mathrm{C}\right)$ & Reference \\
\hline Cicada orni Linnaeus, 1758 & 7.5 & Present study \\
\hline Magicicada cassinii (Fisher, 1852) & 6.8 & Heath, 1967 \\
\hline Cacama valvata (Uhler, 1888) & 9.5 & Heath et al., 1972 \\
\hline Diceroprocta apache (Davis, 1921) & 4.8 & Heath \& Wilkin, 1970 \\
\hline Okanagana hesperia (Uhler, 1872) & 2.8 & Heath, 1972 \\
\hline Okanagodes gracilis Davis, 1919 & 4.9 & Sanborn et al., 1992 \\
\hline Diceroprocta olympusa (Walker, 1850) & 5.8 & Sanborn \& Maté, 2000 \\
\hline Tibicen tibicen (Linnaeus, 1758) & 8.1 & Sanborn, 2000 \\
\hline Platypedia putnami lutea Davis, 1920 & 6.7 & Sanborn et al., $2002 b$ \\
\hline Okanagana striatipes (Haldeman, 1852) & 4.3 & Sanborn et al., 2002a \\
\hline Okanagana utahensis Davis, 1919 & 5.3 & Sanborn et al., 2002a \\
\hline Albanycada albigera (Walker, 1850) & 6.2 & Sanborn et al., 2004 \\
\hline Guyalna bonaerensis (Berg, 1879)* & 11.2 & Sanborn et al., $1995 \mathrm{~b}$ \\
\hline Proarna bergi (Distant, 1892)* & 3.6 & Sanborn et al., 1995a \\
\hline Proarna insignis Distant, $1881^{*}$ & 3.6 & Sanborn et al., 1995a \\
\hline Tibicen winnemanna (Davis, 1912)* & 13.2 (full song 6.7) & Sanborn, 1997, 2000 \\
\hline Pycna semiclara (Germar, 1834)* & 5.0 & Villet et al., 2003 \\
\hline Platypleura capensis (Linnaeus, 1764)* & 3.8 & Sanborn et al., 2003, 2004 \\
\hline Platypleura hirtipennis (Germar, 1834)* & 8.1 & Sanborn et al., 2003, 2004 \\
\hline Platypleura plumosa (Germar, 1834)* & 2.2 & Sanborn et al., 2004 \\
\hline Platypleura wahlbergi Stål, 1855* & 6.4 & Sanborn et al., 2004 \\
\hline Tibicen cultriformis (Davis, 1914)* & 4.4 & Sanborn, 2004 \\
\hline
\end{tabular}


observed by Quartau et al. (2000). The slope of the regressions of $C$. orni are greater than any other analysis performed in cicadas (Sanborn, 2000, 2004; Sanborn \& Maté, 2000; Sanborn et al., 1992, 1995b, 2002b, 2003, 2004; Villet et al., 2003) with the exception of one subset of data in an endothermic species which included partially as well as fully active animals (Sanborn, 2000). As $\mathrm{T}_{\mathrm{a}}$ increases, there is an increase in the $\mathrm{T}_{\mathrm{b}}$ range of active animals in the field. It has been suggested that $C$. orni increase the inter-echeme interval thereby decreasing heat production from the sound producing system as $T_{a}$ increases as a means to maintain calling activity at higher $\mathrm{T}_{\mathrm{a}}$ [and $\mathrm{T}_{\mathrm{b}}$ (Fig. 1)]. We have now shown that the $\mathrm{T}_{\mathrm{b}}$ of calling $C$. orni at elevated $\mathrm{T}_{\mathrm{a}}$ is greater than at lower $\mathrm{T}_{\mathrm{a}}$ making overheating as a result of heat production by the sound system more probable. Elevated $\mathrm{T}_{\mathrm{a}}$ has been shown to inhibit calling activity in other cicada species as well (Heath \& Wilkin, 1970).

Detailed acoustic analyses of the time and frequency domains revealed some variations in the calling song among specimens of $C$. orni and conform to previously known data. Values obtained in the present study for time and frequency variables of $C$. orni song are within the range of variation obtained by Boulard $(1995,2000)$ in Provence (France), and also fall within the observed range of the French populations studied by Pinto-Juma et al. (2005).

Since the production of the calling song is involved in mate attraction, having an important role in pair formation and in species recognition, we also analyzed the possible influence and effect of $T_{b}$ on the calling parameters. Call frequency seems to be independent from $T_{b}$, an expected result considering that frequency is dependent on the structure and physics of the sound producing organ (e.g., Pringle, 1954; Bennet-Clark \& Young, 1992). These results have also been observed in other cicada species (e.g., Marshall \& Cooley, 2000; Villet et al., 2003).

Concerning the temporal parameters, the present study showed no statistically significant correlations of $T_{b}$ for any of the variables studied. Previous studies have shown that there are species for which these parameters are dependent on temperature, but other species where the opposite seems to occur. Temporal parameters have been shown to be dependent on $\mathrm{T}_{\mathrm{b}}$ in the endothermic Tibicen winnemanna (Davis, 1912) (Sanborn, 1997, 2001). In contrast, there was more variability within the population than any influence of $\mathrm{T}_{\mathrm{b}}$ on call parameters in the ectothermic D. olympusa (Sanborn \& Maté, 2000). This appears to be the case for C. orni as well.

Previous results showed echeme duration was the most consistent acoustic variable along the geographical distribution of C. orni, while the inter-echeme duration is quite variable within the species (Pinto-Juma et al., 2005). Moreover, data seem to imply that species recognition, at least by males, is dependent on individuals hearing a minimum echeme duration and inter-echeme interval and these values are near the lower limit of natural variation of the species (Simões \& Quartau, 2006).
Echeme and inter-echeme durations may be the most central properties of the acoustic signal, while temperature induced variation in these acoustic parameters may be irrelevant to mate choice, particularly if females have directional preferences for signal traits. Indeed, these acoustic variables may have different roles in sexual selection and specific mate recognition such as in the case of the cicada Cystosoma saundersii (Westwood, 1842) (Doolan, 1981), where female discriminating ability and preference for males have a central role in sexual selection.

It remains an open question as to whether there are different rules for conspecific call recognition and for assessing the attractiveness of a recognized call in C. orni and how these processes interact to mediate the behavioral expression of mate choice. However, female preferences may constitute an important motor of acoustic signal divergence in $C$. orni, as seen in Greek populations that proved to have longer inter-echeme intervals (PintoJuma et al., 2005).

In fact, the reported longer intervals produced with higher temperatures, besides being an adaptation to allow calling activity at high $T_{a}$ avoiding a lethal increase in $T_{b}$, may also represent a strategy of spending less energy and call for longer periods, maximizing the chances of mating.

Summing up, the present work gives evidence that $C$. orni is an ectothermic cicada, thermoregulating by means of behavioral mechanisms. $\mathrm{T}_{\mathrm{b}}$ is regulated to a range necessary to enable song production and without any significant influence on calling traits. However, the influence of temperature on acoustic signals is something that needs to be considered by anyone performing acoustic analyses. Measurements of $T_{b}$ should be obtained whenever possible. Measurements of $T_{a}$ may not represent the temperature influencing the call parameters unless it is known that the animal is a thermoconforming species and the measurement of $\mathrm{T}_{\mathrm{a}}$ is a true representation of the microenvironment that a species is using as a calling site.

ACKNOWLEDGEMENTS. J. Sueur provided logistical support making work in France possible. Two anonymous reviewers made comments to improve the manuscript. This study was partially supported financially by the Centre for Environmental Biology (FCT).

\section{REFERENCES}

Bennet-Clark H.C. 1998: How cicadas make their noise. Sci. Am. 278: 36-39.

Bennet-Clark H.C. \& Young D. 1992: A model of the mechanism of sound production in cicadas. J. Exp. Biol. 173: 123-153.

Boulard M. 1995: Postures de cymbalisation, cymbalisations et cartes d'identité acoustique de cigales. 1. Généralités et espèces méditerranéennes (Homoptera, Cicadoidea). EPHE Biol. Evol. Ins. 7/8: 1-72.

BOUlARD M. 2000: Appareils, productions et communications sonores chez les insectes en général et chez les cigales en particulier. EPHE Biol. Evol. Ins. 13: 75-110.

Claridge M.F. 1985: Acoustic signals in the Homoptera: behavior, taxonomy, and evolution. Annu. Rev. Entomol. 30: 297-317. 
Cloudsley-Thompson J.L. 1960: Some aspects of the fauna of the coastal dunes of the Bay of Biscay. Entomol. Mon. Mag. 96: $49-53$.

Cloudsley-Thompson J.L. \& SAnkey J.H.P. 1957: Some aspect of the fauna of the district around the Etang-de-Berre, Bouches-du-Rhone, France. Ann. Mag. Nat. Hist. 10: 417-424.

Doolan J.M. 1981: Male spacing and the influence of female courtship behaviour in the bladder cicada, Cystosoma saundersii Westwood. Behav. Ecol. Sociobiol. 9: 269-276.

Fonseca P.J. \& Revez M.A. 2002: Song discrimination by male cicadas Cicada barbara lusitanica (Homoptera, Cicadidae). $J$. Exp. Biol. 205: 1285-1292.

Gogala M., Popov A.V. \& Ribaric D. 1996: Bioacoustics of singing cicadas of the western Palaearctic: Cicadetta tibialis (Panzer) (Cicadoidea: Tibicinidae). Acta Entomol. Slov. 4: $45-62$.

Heath J.E. 1967: Temperature responses of the periodical "17year" cicada, Magicicada cassini (Homoptera, Cicadidae). Am. Midl. Nat. 77: 64-67.

Heath J.E. \& WiLKIn P.J. 1970: Temperature responses of the desert cicada, Diceroprocta apache (Homoptera, Cicadidae). Physiol. Zool. 43: 145-154.

Heath J.E., Wilkin P.J. \& Heath M.S. 1972: Temperature responses of the cactus dodger, Cacama valvata (Homoptera, Cicadidae). Physiol. Zool. 45: 238-246.

Heath M.S. 1972: Temperature requirements of the cicada Okanagana striatipes beameri: A study from Flagstaff, Arizona. Plateau 45: 31-40.

Marshall D.C. \& Cooley J.R. 2000: Reproductive character displacement and speciation in periodical cicadas, with description of a new species, 13-year Magicicada neotredecim. Evolution 54: 1313-1325.

MAY M.L. 1985: Thermoregulation. In Kerkut G.A. \& Gilbert L.I. (eds): Comprehensive Insect Physiology, Biochemistry, and Pharmacology. Vol. 4. Pergamon Press, New York, pp. 507-552.

Pinto-Juma G., Simões P.C., Seabra S.G. \& Quartau J.A. 2005: Calling song structure and geographical variation in Cicada orni L. (Hemiptera: Cicadidae). Zool. Stud. 44: 81-94.

Popov A.V. 1975: The structure of the tymbals and the characteristics of the sound signals in singing cicadas (Homoptera, Cicadidae) in the southern regions of the USSR. Entomol. Rev. 54: 7-35.

Popov A.V., Beganovic A. \& Gogala M. 1997: Bioacoustics of singing cicadas of the western Palaearctic: Tettigetta brullei (Fieber 1876) (Cicadoidea: Tibicinidae). Acta Entomol. Slov. 5: $89-101$.

PrINGLE J.W.S. 1954: A physiological analysis of cicada song. $J$. Exp. Biol. 31: 525-560.

Quartau J.A., Seabra S. \& Sanborn A. 2000: Effect of ambient air temperature on some temporal parameters of the calling song of Cicada orni Linnaeus, 1758 (Hemiptera: Cicadidae) in Portugal. Acta Zool. Cracov. 43: 193-198.

SANBorn A.F. 1997: Body temperature and the acoustic behavior of the cicada Tibicen winnemanna (Homoptera: Cicadidae). J. Insect Behav. 10: 257-264.

SANBorn A.F. 1998: Thermal biology of cicadas (Homoptera: Cicadoidea). Trends Entomol. 1: 89-104.

SANBORN A.F. 2000: Comparative thermoregulation of sympatric endothermic and ectothermic cicadas (Homoptera: Cicadidae: Tibicen winnemanna and Tibicen chloromerus). J. Comp. Physiol. (A) 186: 551-556.

SANBORN A.F. 2001: Timbal muscle physiology in the endothermic cicada Tibicen winnemanna (Homoptera: Cicadidae). Comp. Biochem. Physiol. (A) 130: 9-19.
SAnBorn A.F. 2002: Cicada thermoregulation (Hemiptera, Cicadoidea). Denisia 4: 455-470.

SANBORN A.F. 2004: Thermoregulation and endothermy in the large western cicada Tibicen cultriformis (Hemiptera: Cicadidae). J. Therm. Biol. 29: 97-101.

SAnBorn A.F. 2005: Acoustic signals and temperature. In Drosopoulos S. \& Claridge M.F. (eds): Insect Sounds and Communication: Physiology, Behaviour, Ecology and Evolution. CRC Press, Boca Raton, pp. 111-125.

SANBORn A.F. \& MATÉ S. 2000: Thermoregulation and the effect of body temperature on call temporal parameters in the cicada Diceroprocta olympusa (Homoptera: Cicadidae). Comp. Biochem. Physiol. (A) 125: 141-148.

SAnBorn A.F. \& Phillips P.K. 1992: Observations on the effect of a partial solar eclipse on calling in some desert cicadas (Homoptera: Cicadidae). Fla Entomol. 75: 285-287.

Sanborn A.F., Heath J.E. \& Heath M.S. 1992: Thermoregulation and evaporative cooling in the cicada Okanagodes gracilis (Homoptera: Cicadidae). Comp. Biochem. Physiol. (A) 102: 751-757.

Sanborn A.F., Heath J.E., Heath M.S. \& Noriega F.G. 1995a: Thermoregulation by endogenous heat production in two South American grass dwelling cicadas (Homoptera: Cicadidae: Proarna). Fla Entomol. 78: 319-328.

Sanborn A.F., Heath M.S., Heath J.E. \& Noriega F.G. 1995b: Diurnal activity, temperature responses and endothermy in three South American cicadas (Homoptera: Cicadidae: Dorisiana bonaerensis, Quesada gigas, and Fidicina mannifera). $J$. Therm. Biol. 20: 451-460.

Sanborn A.F., Breitbarth J.H., Heath J.E. \& Heath M.S. 2002a: Temperature responses and habitat sharing in two sympatric species of Okanagana (Homoptera: Cicadoidea). West. North Am. Nat. 62: 437-450.

Sanborn A.F., Noriega F.G. \& Phillips P.K. 2002b: Thermoregulation in the cicada Platypedia putnami var. lutea with a test of a crepitation hypothesis. J. Therm. Biol. 27: 365-369.

SAnBorn A.F., Villet M.H. \& Phillips P.K. 2003: Hot-blooded singers: endothermy facilitates crepuscular signaling in African platypleurine cicadas (Hemiptera: Cicadidae: Platypleura spp.). Naturwissenschaften 90: 305-308.

Sanborn A.F., Villet M.H. \& Phillips P.K. 2004: Endothermy in African platypleurine cicadas: the influence of body size and habitat (Hemiptera: Cicadidae: Platypleura spp.). Physiol. Biochem. Zool. 77: 816-823.

Sanborn A.F., Phillips P.K., Heath J.E. \& Heath M.S. 2011: Comparative thermal adaptation in cicadas (Hemiptera: Cicadidae) inhabiting Mediterranean ecosystems. J. Therm. Biol. 36: $150-155$.

Simões P.C. \& Quartau J.A. 2006: Selective responsiveness in males of Cicada orni to conspecific and allospecific calling songs (Hemiptera: Cicadidae). Entomol. Gen. 29: 47-60.

SPecht R. 2002: Avisoft-SASLab Pro-Sound Analysis and Synthesis Laboratory, Version 4.1d. Berlin.

Sueur J. \& SANBorn A.F. 2003: Ambient temperature and sound power of cicada calling songs (Hemiptera: Cicadidae: Tibicina). Physiol. Entomol. 28: 340-343.

VILLET M.H. 1992: Responses of free-living cicadas (Homoptera: Cicadidae) to broadcasts of cicada songs. $J$. Entomol. Soc. Sth. Afr. 55: 93-97.

Villet M.H., SAnborn A.F. \& Phillips P.K. 2003: Endothermy and chorusing behaviour in the African platypleurine cicada Pycna semiclara (Hemiptera: Cicadidae). Can. J. Zool. 81: $1437-1444$

Received February 22, 2011; revised and accepted March 18, 2011 